\title{
Performance-based assessment of response reduction factor of RC-elevated water tank considering soil flexibility: a case study
}

\author{
Kashyap N. Patel ${ }^{1}$.. Jignesh A. Amin ${ }^{1}$
}

Received: 31 July 2017 / Accepted: 20 July 2018 / Published online: 28 July 2018

(c) The Author(s) 2018

\begin{abstract}
The seismic design codes/standards of most countries include the nonlinear response of a structure implicitly through a response reduction/modification factor $(R)$. It is the factor by which the actual base shear should be reduced to find the design base shear during design basic earthquake considering nonlinear behavior and deformation limits of structures. In the present study, attempts are made to determine the ' $R$ ' factors of four existing RC staging elevated water tanks, which are designed as per draft Indian standards for seismic design of liquid and RC designs and having a ductile detailing considering the effects of soil flexibility. The elevated RC water tanks are analyzed using displacement controlled non-linear static pushover analysis to evaluate the base shear capacity and ductility of tank considering soil flexibility. The ' $R$ ' factor is obtained for four realistic designs of elevated RC water tanks having different capacities at two performance levels. The evaluated values of ' $R$ ' factor are compared with the values suggested in the design code. The results of the study show that the flexibility of supporting soil has considerable effect on response reduction factor, period and overall performance of water tank, indicating that idealization of fixity at base may be seriously mistaken for soft soils. All the studied water tanks were designed with higher safety margin than that of specified in Indian Standards.
\end{abstract}

Keywords Response reduction factor $\cdot$ Soil flexibility $\cdot$ Ductility factor $\cdot$ Strength factor $\cdot$ Pushover analysis

\section{Introduction}

Elevated RC staging water tanks have an essential role in water distribution network. Therefore, they should remain operational after earthquakes for essential needs. Various deficiencies for the poor seismic performance of elevated water tanks during past earthquakes such as improper structural design of elements and joints, low reserve strength and ductility, and the effect of soil flexibility have been reported in the previous studies (Rai 2003; Dutta et al. 2000). Current force-based design procedure adopted by most seismic design codes allows the seismic design of structures to be based on static or dynamic analyses of elastic models of the structure using elastic design spectra. The codes anticipate that structures will undergo inelastic deformations under strong seismic events; therefore, such inelastic behavior is usually incorporated into the design

Jignesh A. Amin

jamin_svit@yahoo.com

1 Sardar Vallabhbhai Patel Institute of Technology, Vasad-388306, Gujarat, India by dividing the elastic spectra by a factor $R$, which reduces the spectrum from its original elastic demand level to a design level. The values of the $R$ factor basically depend on the structural ductility factor and over-strength. For a structure supported on flexible foundation, the consideration of the soil flexibility in analysis increases the elastic period and damping of the structure-foundation system and subsequently it affect the structural ductility. This implies that the response reduction factors, which are currently not affected by the soil flexibility, could be altered. The values of response reduction factor of RC elevated water tank are given in IITK-GSDM guidelines (IITK-GSDM guidelines for Seismic design of liquid storage tanks 2007) and IS 1893 (Part-II) for Seismic design of liquid storage tanks (Draft IS 1893 2006; BIS IS 1893 2014), which is derived empirically based on engineering judgment. The fourth revision of seismic design code was published in 1984. After Bhuj earthquake in 2001 and considering the fact that significant advancements have taken place in the field of earthquake engineering, fifth revision of IS 1893 (Part-1), general provision for earthquake resistant buildings and structures was published in 2002 (IS 1893 2002). However, 
the draft code for seismic design of liquid storage tanks IS 1893 (Part-2) was prepared in 2006 and final version was published in 2014. IS1893:1984 recommended the single degree of freedom idealization of tank; whereas draft as well as the final version of IS 1893 (Part-II) 2014 recommended two-degree of freedom idealization for analysis of elevated tanks and the flexibility of bracing beam is included in the evaluation of lateral stiffness of tank staging. The values of response reduction factor of elevated water tank adopted by different codes/standards are summarized in Table 1. The recent revision of IS 1893 (Part-2): 2014 had increased the value " $R$ " factor of special moment resisting RC staging water tank to 4 from the 2.5 suggested in 2006 version of the draft code. The existing literature in this area does not provide any specific basis on which a value of 4 is assigned for ductile moment resisting RC staging elevated water tanks in the IS 1893 (Part-2): 2014.

Different aspects of the response reduction factor of various structural systems have been investigated and essential weaknesses have been pointed out by many researcher. Mondal et al. (2013) estimated the real values of response reduction factor of actual RC moment frame structure designed and detailed using the Indian codes for earthquake and RC designs and for ductile detailing. Authors concluded that codes recommend higher than real value of ' $R$ ' for RC frame. Tamboli and Amin (2015) evaluated the ' $R$ ' factor of RC frame strengthened using the different types of bracing systems and concluded that type and arrangement of bracing systems have significant impact on the ' $R$ ' factor. Masoudi et al. (2012) discuss the seismic behavior and failure mechanism of $\mathrm{RC}$ frame and shaft-supported tanks under severe earthquakes considering the $P-\Delta$ effects by performing linear and nonlinear response history analyses. Ghateh et al. (2015) presented a methodical approach to determine the response modification factors for total 48 elevated tanks of different capacities and RC frame dimensions commonly used in industry. They have suggested not to use the same response reduction factor for tanks having a different staging height and capacity. Patel et al. (2014) evaluated component-wise response reduction factor of elevated water tanks having equal staging height and different capacities. They concluded that the value of response reduction factor for RC staging tank is significantly influenced by time period, capacity of tank, and seismic

Table 1 Values of ' $R$ ' from different codes

\begin{tabular}{ll}
\hline Codes & $R$ value \\
\hline IBC 2000/FEMA 368 (IBC 2000; FEMA 368 2000) & $1.5-3.0$ \\
AWWA D110 (1995) & $2-2.75$ \\
ACI 350.3 (2001) & $2.0-4.75$ \\
RCC frame support IITK-GSDM guidelines (SMRF)/Draft & 2.5 \\
$\quad$ code IS:1893 (Part-II) & \\
RCC frame support IS:1893 (Part-2):2014 (SMRF) & 4 \\
\hline
\end{tabular}

zone. The possible serious effects of neglecting soil flexibility and their effects on structural safety have been evaluated by many researchers (Dutta et al. 2004; Halabian and Erfani 2013; Livaoglu and Dogangun 2007). Dutta et al. (2004) studied the effect of soil flexibility on the dynamic characteristics of RC frame staging tanks having different configurations and concluded that analysis without considering soil flexibility may lead to lower or higher estimation of seismic base shear of RC frame staging tanks considering fluid-structure interaction. Halabian and Erfani (2013) evaluated the effect of foundation flexibility and structural strength on response reduction factor of RC frame buildings.

The aim of the present study is component-wise evaluation of response reduction factor of the four existing realistic $\mathrm{RC}$ water tanks considering the effects of soil flexibility and comparing these values with the values given in the seismic design code. All tanks are located in different parts of Gujarat, India and were designed and detailed as per the Indian codal provisions IS: 456-2000 (BIS IS 456 2000), IITK-GSDM guidelines/Draft IS 1893 (Part-II) and IS: 13920-1993 (BIS IS 13920 1993) by different design engineers.

\section{Concept of ' $R$ ' factor}

The ' $R$ ' factors are essential seismic design tools, which indicate the level of inelasticity expected in structural systems during an earthquake event. This factor intended to account for both damping and ductility inherent in structural systems at the displacements great enough to approach the maximum displacement of the systems. The ' $R$ ' factor reflects the capability of structure to dissipate energy through inelastic behavior. The response reduction factor ' $R$ ' depends on various components such as overstrength factor $\left(R_{\mathrm{s}}\right)$, ductility factor $\left(R_{\mu}\right)$, redundancy factor $\left(R_{\mathrm{R}}\right)$ and damping factor $\left(R_{\zeta}\right)$. According to ATC19 (1995), it is described as

$R=R_{s} \times R_{\mu} \times R_{R} \times R_{\zeta}$.

\section{Strength factor $\left(R_{s}\right)$}

Strength factor $\left(R_{\mathrm{S}}\right)$ accounts for the yielding of a structure at load higher than the design load due to various partial safety factors, strain hardening, oversized members and confinement of concrete. Non-structural elements also contribute to the overstrength. The overstrength factor generally varies with seismic zones, height of structure and design gravity loads/ capacity of water tank. The strength factor $\left(R_{\mathrm{S}}\right)$ is defined as a ratio of maximum base shear $\left(V_{0}\right)$ to the design base shear $\left(V_{\mathrm{d}}\right)$

$R_{\mathrm{s}}=V_{0} / V_{\mathrm{d}}$ 


\section{Ductility factor $\left(R_{\mu}\right)$}

The ductility factor $\left(R_{\mu}\right)$ is a measure of the global nonlinear response of a structural system in terms of its plastic deformation capacity. Miranda and Bertero (1994) summarized and reworked the $R_{\mu}-\mu-T$ relationships developed by a number of researchers including Riddell and Newmark (1979), Newmark and Hall (1982) and Krawinkler and Nasser (1992) for soft, alluvium and rock soil sites. In the present study, the $R_{\mu}-\mu-T$ relationships established by Miranda and Bertero (Riddell and Newmark 1979) are used. The Miranda and Bertero's equations for ductility factor shown below were developed using 124 ground motions recorded on a different soil conditions, and assumed $5 \%$ of critical damping:

$R_{\mu}=\frac{\mu-1}{\Phi}+1$,

where $\mu$ is the displacement ductility ratio generally defined as the ratio of maximum displacement to the displacement at yield. For rock sites,

$\Phi=1+\frac{1}{10 T-\mu T}-\frac{1}{2 T} e^{-1.5(\ln (T)-0.6)^{2}}$.

For alluvium sites,

$\Phi=1+\frac{1}{12 T-\mu T}-\frac{2}{5 T} e^{-2(\ln (T)-0.2)^{2}}$.

For soft soil sites,

$\Phi=1+\frac{T_{\mathrm{g}}}{3 T}-\frac{3 T_{\mathrm{g}}}{4 T} e^{-3\left(\ln \left(T / T_{\mathrm{g}}\right)-0.25\right)^{2}}$,

where $T_{\mathrm{g}}$ is the predominant time period of the ground motion.

\section{Redundancy factor $\left(R_{R}\right)$}

Yielding at one location in the structure does not indicate yielding of the whole structure. Hence, the load distribution, due to redundancy of the structure, provides additional safety margin. RC structure with multiple lateral load-resisting frames is normally considered as redundant structure, because each of the seismic frames is designed and detailed to transfer the seismic forces to the soil. Following the conservative assumption, $R_{\mathrm{R}}=1.0$ is used in this study.

\section{Damping factor $\left(R_{\zeta}\right)$}

The damping factor $\left(R_{\zeta}\right)$ takes into accounts the effect of 'added' viscous damping for a structures having supplementary energy dissipating devices. Without any such devices, the damping factor is generally taken as one.

\section{Description of the existing water tank considered in this study}

In the present study, ' $R$ ' factors of four existing RC-elevated water tanks having capacities of 140, 480, 1000 and $2200 \mathrm{~m}^{3}$ are evaluated with and without considering the flexibility of soil. All investigated water tanks are located in different parts of Gujarat, India and were designed and detailed using the code provisions IS: 456-2000, Draft IS1893 (Part-II) 2006 and IS: 13920-1993 by different design engineers. Live load on roof slab/top dome is assumed as $0.5 \mathrm{kN} / \mathrm{m}^{2}$. Damping in the structures is considered to be $5 \%$ of the critical. The typical configurations of staging system of study water tanks are shown in Fig. 1. All the water tanks had a raft foundation and supported on medium soil. The brief structural details and description of considered elevated water tanks are shown in Tables 2 and 3.

\section{Modeling of soil flexibility}

The behavior of the structures depends mainly on its mass, stiffness, supporting soil properties and foundation type. When the lateral forces, such as seismic forces, act on these systems, the displacement of structure and soil is not independent of each other. The process by which the response of the soil affects the motion of the structure and the motion of the structure affects the response of the soil is termed as soil-structure interaction. Conventional structural designs neglect the effects of soil flexibility. Neglecting soil flexibility is acceptable for light structures such as low rise buildings and simple rigid-retaining walls on relatively stiff soil. The behavior of soil can be conveniently simulated using a set of elastic springs. The underneath soil flexibility can be modeled with equivalent translation, rocking and torsional elastic stiffness based on soil properties and using equations given by Whitman and Richart (Ghazetas 1983) (Table 4). In this study, three different properties of soil stratum, i.e., hard, medium and soft soil conditions were considered to study the effect of soil flexibility. The linear elastic material behavior was assumed for soil. The elastic properties and calculated equivalent spring constants of considered soils in different direction are shown in Table 5.

\section{Pushover analysis of finite element model of study water tanks}

SAP 2000 V15 (Structural Analyis software 2000) software is used to perform nonlinear static pushover analysis of study water tanks. The RC beams and columns are modeled as 


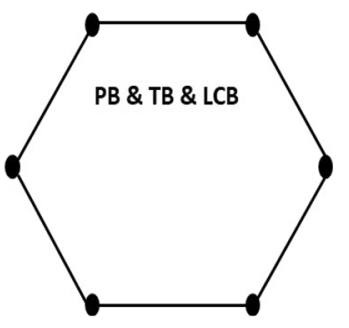

(a) $140 \mathrm{~m}^{3}$ tank.

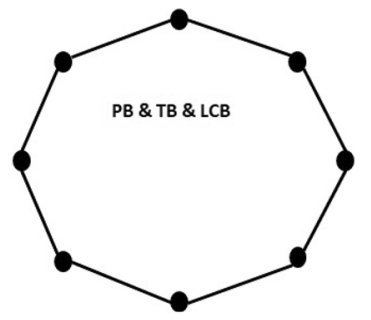

(b) $480 \mathrm{~m}^{3} \operatorname{tank}$

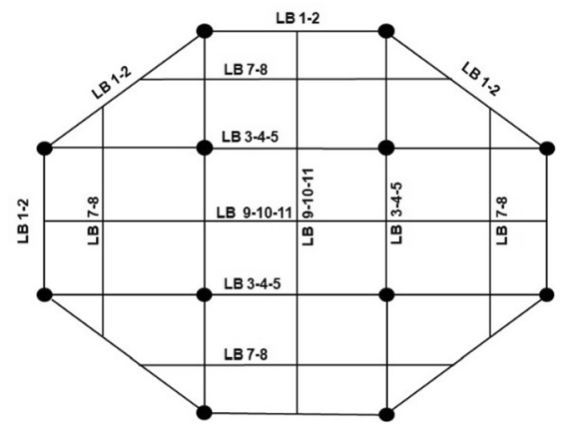

(c) $1000 \mathrm{~m}^{3}$

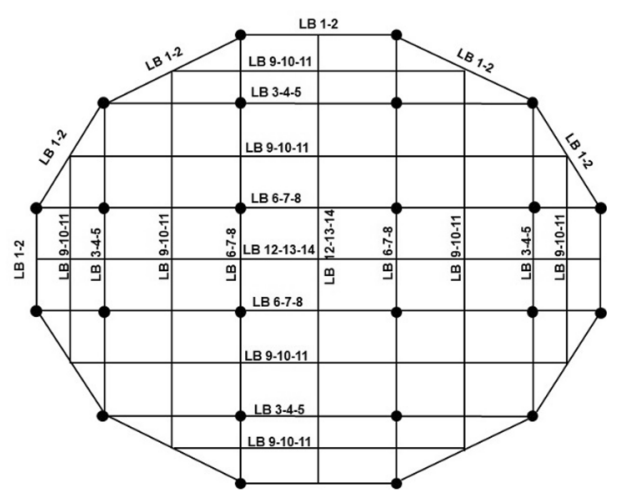

(d) $2200 \mathrm{~m}^{3}$ tank

Fig. 1 Plan configuration of study water tanks

three-dimensional frame elements with centerline dimension. Different parameters such as weight of staging, weight of container, convective mass, impulsive mass, height of impulsive mass, height of convective mass and C.G of container are computed as per guidelines given by IS 1893 (Part-II) guidelines for seismic design of water tanks. The convective mass and impulsive mass are assigned at the appropriate height of the structure as per the codal provisions, whereas self-weight of the container is assigned as uniformly distributed load on the top circular beam. Walls and domes/slabs are assumed to behave as rigid diaphragms. The diaphragm action of a slab is considered by assigning a rigid link at the floor level of container. Damping ratio of 5\% is assumed. Flexural $\left(\mathrm{M}_{3}\right)$, axial biaxial moment $\left(P-M_{2}-M_{3}\right)$ plastic hinges are assigned to each ends of the beams and columns, respectively, where the resultant moments under gravity and lateral loads are maximum. Shear hinges were assigned at the ends of a beam. The idealized force-deformation curve and acceptance criteria for various performance levels in beams and columns have been considered as per FEMA 356 guidelines. The non-linear load-deformation relation (FEMA 356 (2000)) adopted for the pushover analysis is shown in Fig. 2. It is described by linear response from A (unloaded condition) to an effective yield B, then a linear response at reduced stiffness from point $\mathrm{B}$ to $\mathrm{C}$, then sudden reduction in lateral load resistance to point $\mathrm{D}$, then response at reduced resistance to $\mathrm{E}$, and final loss of resistance thereafter. The slope from point $\mathrm{B}$ to $\mathrm{C}$, ignoring effects of gravity loads acting through lateral displacements, shall be taken as $0-10 \%$ of the initial slope unless an alternate slope is justified by experiment or analysis. Point $C$ shall have an ordinate equal to the strength of the component and an abscissa equal to the deformation at which significant strength degradation begins. Line DE represents the residual strength of the member. Three performance levels, Immediate Occupancy (IO), Life Safety (LS), and Collapse Prevention (CP) are considered in this study as specified in guidelines such as FEMA-356 and ATC-40. Description of the expected damage condition of the RC frame staging as par FEMA 356 seismic performance levels has been summarized in Table 6 .

Figure 3 shows the modeling of a typical tank for the pushover analysis. In pushover analysis, first a 'gravity push' was applied with full dead load, convective mass, impulsive mass and $25 \%$ of live load. The pushover analysis is load controlled up to the first yielding and thereafter it is displacement controlled. The node associated with the center of mass of container is used as target node to apply the push loading. From the pushover analysis, the base shear $(\mathrm{V})$ versus roof displacement $\left(\Delta_{\text {roof }}\right)$ curve of the structure, usually called static pushover curve, is obtained.

The definition of response reduction factor ' $R$ ' is integrated to the selected performance limit state of the structure. The Indian standard IS: 1893 does not describe the limit state corresponding to which values of ' $R$ ' factor are suggested in this code. In this study, two performance limits are considered for the computation of ' $R$ ' of study water tanks. From past two decades, the concept of performancebased seismic design has come into practice. Performancebased provisions describe different performance limits for various types of members (i.e., ATC-40 (1996), FEMA 356). The performance limits can be classified as global/structural limits and local/element limits. The global limits are generally based on vertical load capacity, lateral load capacity and lateral drift of structure. In this study, the Performance Limit 1 or PL1 corresponds to the life safety limit state of RC frame member defined in FEMA-356. The PL1 is defined at the member level in terms of the allowable plastic 
Table 2 Detailed descriptions of RC tanks and members

\begin{tabular}{lll}
\hline Capacity $\left(\mathrm{m}^{3}\right)$ & 140 & 480 \\
\hline Earthquake zone & Zone-III & Zone-III \\
Type of soil & Medium soil & Medium soil \\
Diameter of staging (m) & 6 & 9 \\
Height of staging $(\mathrm{m})$ & 18 & 18 \\
Tie beam levels & Plinth $+4.5 \mathrm{~m} \mathrm{c} / \mathrm{c}$ & Plinth +4.5 m c/c \\
No. of columns & 6 & 8 \\
Top dome (mm) & 100 & 100 \\
Top ring beam (mm) & $170 \times 300$ & $350 \times 300$ \\
Cylindrical wall (mm) & 170 & 170 \\
Bottom ring beam (mm) & $300 \times 300$ & $400 \times 300$ \\
Lower circular ring beam (mm) & $400 \times 800$ & $500 \times 1000$ \\
Bottom dome (mm) & 170 & 175 \\
Conical dome (mm) & 170 & 200 \\
Braces (mm) & $300 \times 530$ & $300 \times 600$ \\
Columns (mm) & 500 & 600 \\
Reinforcement in tie beam and plinth beam & $4-16 \#$ & $6-16 \#$ \\
Reinforcement in columns & $12-16 \#$ & $12-16 \#$ \\
Reinforcement in lower circular beam & $6-20+2-16 \#$ & $3-25+2-20 \#$ \\
\hline
\end{tabular}

Table 3 Detailed descriptions of RC tanks and members

\begin{tabular}{|c|c|c|}
\hline Capacity $\left(\mathrm{m}^{3}\right)$ & 1000 & 2200 \\
\hline Zone & Zone-V & Zone-III \\
\hline Soil type & Hard soil & Medium soil \\
\hline Height of staging $(\mathrm{m})$ & 20 & 23 \\
\hline Diameter of staging (m) & 16.25 & 22.75 \\
\hline Height of container (m) & 5 & 7 \\
\hline Wall thickness (mm) & 230 & 250 \\
\hline Top slab thickness (mm) & 170 & 175 \\
\hline Bottom slab thickness (mm) & 230 & 250 \\
\hline Height of staging (m) & 15 & 18.4 \\
\hline Tie beam levels $(\mathrm{m})$ & Plinth $+5 \mathrm{~m} \mathrm{c} / \mathrm{c}$ & Plinth + 4.6 m \\
\hline Column size (mm) & 650 & 600 \\
\hline Reinforcement in column (No-dia) & $16-20 \mathrm{~mm}$ & $8-20 \mathrm{~mm}$ \\
\hline Plinth beam $(\mathrm{mm} \times \mathrm{mm})$ & $400 \times 600$ & $300 \times 500$ \\
\hline Tie of beam $(\mathrm{mm} \times \mathrm{mm})$ & $400 \times 600$ & $300 \times 500$ \\
\hline Bottom slab beam $(\mathrm{mm} \times \mathrm{mm})$ & $350 \times 1200$ & $350 \times 950$ \\
\hline No. of column & 12 & 24 \\
\hline Length of column (m) & 5 & 4.6 \\
\hline Reinforcement in columns (No-dia) & 16-20\# & $8-20 \#$ \\
\hline Ground beam 1,2 & $\begin{array}{l}2-16 \#+4-20 \# \text { (top) } \\
6-16 \# \text { (bottom) }\end{array}$ & $\begin{array}{l}2-16 \#+3-20 \#(\text { top) } \\
4-16 \#(\text { bottom) }\end{array}$ \\
\hline Ground beam 3,4 & 4-16\#+4-20\#(top),4-16\#+2-20\#(bottom) & $2-16 \#+3-20 \#$ (top),4-16\#(bottom) \\
\hline Ground beam 5,6 & - & 2-16\#+5-20\#(top),4-20\#(bottom) \\
\hline Tie beam 1,2 & 4-16\#+3-20\#(top)4-16\#+2-20\#(bottom) & 2-16\#+4-20\#(top)4--16\#(bottom) \\
\hline Tie beam 3,4 & 4-16\#+4-20\#(top),4-16\#+3-20\#(bottom) & $2-16 \#+5-20 \#$ (top),4-16\#(bottom) \\
\hline Tie beam 5,6 & - & 5-20\#(top),4--20\#(bottom) \\
\hline Lower ring beam $\mathrm{B} 1, \mathrm{~B} 2$ & 4-20\#+6-25\#(top),5-25\#+3-12\#(bottom) & $2-20 \#+2-16 \#$ (top), $5-16 \#+3-10 \#$ (bottom) \\
\hline Lower ring beam B3,B4,B5 & $4-20 \#+8-25 \#+$ (top), 10-25\# & 4-20\#+5-25\# (top),6-20\# \\
\hline Lower ring beam $\mathrm{B} 6, \mathrm{~B} 7, \mathrm{~B} 8$ & $2-16 \#+6+20 \#+($ top), $6-20 \#$ & 3-20\#+(top),7-20\# \\
\hline Lower ring beam B9,B10,B11 & 4-16\#+5-20\#(top),8-20\#(bottom) & 2-20\#(top),4-20\#(bottom) \\
\hline Lower ring beam B12,B13,B14 & - & 4-20\#+3-25\#(top),5-20\#(bottom) \\
\hline
\end{tabular}


Table 4 Equivalent spring stiffness for raft foundation

\begin{tabular}{lllll}
\hline Mode & Vertical & Horizontal & Rocking & Torsion \\
\hline Stiffness & $\frac{4 \mathrm{G} R}{1-\mu}$ & $\frac{8 \mathrm{G} R}{2-\mu}$ & $\frac{8 \mathrm{G} R^{3}}{3(1-\mu)}$ & $\frac{16 \mathrm{G} R^{3}}{3}$ \\
Mass ratio & $\frac{m(1-\mu)}{4 \rho R^{3}}$ & $\frac{m(2-\mu)}{8 \rho R^{3}}$ & $\frac{3 I_{x}(2-\mu)}{8 \rho R^{3}}$ & $\frac{I_{z}}{\rho R^{5}}$ \\
Damping ratio & $\frac{0.425}{\bar{m}^{0.5}}$ & $\frac{0.29}{\bar{m}^{0.5}}$ & $\frac{0.15}{(1+\bar{m}) \bar{m}^{0.5}}$ & $\frac{0.50}{(1+2 \bar{m})}$ \\
\hline
\end{tabular}

$I_{\mathrm{x}}, I_{\mathrm{z}}=$ mass moments of inertia around horizontal and vertical axes, respectively; damping ratio $=C / C_{\mathrm{cr}}$, where $C_{\mathrm{cr}}=2(\mathrm{Km}){ }^{1 / 2}$ or $\mathrm{C}_{\mathrm{cr}}=2(\mathrm{KI})^{1 / 2}$ for translational or rotational modes of vibration. With $I=I_{\mathrm{x}}$ or $I_{\mathrm{z}}$ for rocking or torsion, respectively

Table 5 Elastic soil properties and spring stiffness considered in water tank

\begin{tabular}{llcccc}
\hline Type of soil & Degrees of freedom & $\begin{array}{l}\text { Spring constant } \\
140 \mathrm{~m}^{3} \\
\left(\mathrm{kN} / \mathrm{m} / \mathrm{m}^{2}\right)\end{array}$ & $\begin{array}{l}\text { Spring constant } \\
480 \mathrm{~m}^{3} \\
\left(\mathrm{kN} / \mathrm{m}^{2} / \mathrm{m}^{2}\right.\end{array}$ & $\begin{array}{l}\text { Spring constant } \\
1000 \mathrm{~m}^{3} \\
\left(\mathrm{kN} / \mathrm{m} / \mathrm{m}^{2}\right)\end{array}$ & $\begin{array}{l}\text { Spring constant } \\
2200 \mathrm{~m}^{3} \\
\left(\mathrm{kN} / \mathrm{m}^{2} / \mathrm{m}^{2}\right)\end{array}$ \\
\hline \multirow{2}{*}{ Hard } & Horizontal & 42096.2 & 37678.88 & 15852.45 & 12533.36 \\
& Vertical & 63144.3 & 56518.32 & 23778.69 & 18800.04 \\
& Rocking & 604674.18 & 677375.95 & 1613908 & 2043851 \\
& Torsion & 604674.18 & 677375.95 & 1613908 & 2043851 \\
\multirow{3}{*}{ Medium } & Horizontal & 24177.77 & 21640.7 & 9104.78 & 7198.47 \\
& Vertical & 36266.66 & 32461.05 & 13657.18 & 10797.72 \\
& Rocking & 347291.9 & 389047.91 & 926941.1 & 1173877 \\
\multirow{5}{*}{ Soft } & Torsion & 347291.9 & 389047.91 & 926941.1 & 1173877 \\
& Horizontal & 5766.29 & 5161.21 & 2171.45 & 1716.807 \\
& Vertical & 8649.68 & 7741.82 & 3257.18 & 2575.211 \\
& Rocking & 83827.6 & 92786.29 & 221071.6 & 279964.7 \\
& Torsion & 83827.6 & 92786.29 & 221071.6 & 279964.7 \\
\hline
\end{tabular}

hinge rotation at member ends. Tables 7 and 8 provide the local deformation limits specified by FEMA-356 in terms of allowable plastic hinge rotations of beam and column element, respectively, in a $\mathrm{RC}$ special moment-resisting frame (SMRF) element at different performance levels for flexural failures of an element. The Performance Limit 2 or PL2 is defined as the point corresponding to the maximum base shear on the force-displacement relationship curve of structures or in terms of the maximum drift ratio of structure, whichever attained earlier. The limit state PL2 is defined at the structural level in terms of the ultimate capacity of the structural system. The various performance levels in terms of the maximum drift ratio specified in ATC-40 are shown in Table 9. The global performance limit PL2 is defined by a maximum drift ratio of $0.33 V_{\mathrm{i}} / P_{\mathrm{i}}$ at structural stability. For all the water tanks considered in this study, having a maximum base shear $\left(V_{\mathrm{i}}\right)$ is nearly $6 \%$ of the total seismic weight of tank. Therefore, the allowable drift ratio corresponding to structural stability is roughly equal to 0.02 , which is similar or very close to limit corresponding to life safety.

The performance limit PL1 is defined at the member/local level in terms of the maximum plastic rotation at the ends of
$\mathrm{RC}$ frame member. This limit state is monitored continuously at each step of the pushover analysis, and the performance point PL1 is noted when the plastic rotation of any beam or column member reaches to limit states defined as given in Tables 7 and 8 , respectively. The second performance limit state PL2 is defined at the global/structural level as the point on the pushover curve corresponding to the maximum base shear or point corresponding to the maximum drift ratio of 0.02, whichever attained earlier. For all considered water tanks, the maximum base shear capacity of structures on pushover curve reached earlier than the maximum drift ratio of 0.02 during NSPA. Therefore, the performance limit state PL2 is considered corresponding to the maximum base shear on pushover/capacity curves in this study. The results of pushover analysis show that the beams of RC frame staging enter into inelastic range before the columns. Generally, design of staging using IS 13920, i.e., capacity design concept leads to strong column weak beam design. The behavior of frame staging elevated water tank supporting a large convective and impulsive mass at the top is completely different than SMRF typically used in building, because in building the mass of the structure is distributed at different story levels. 


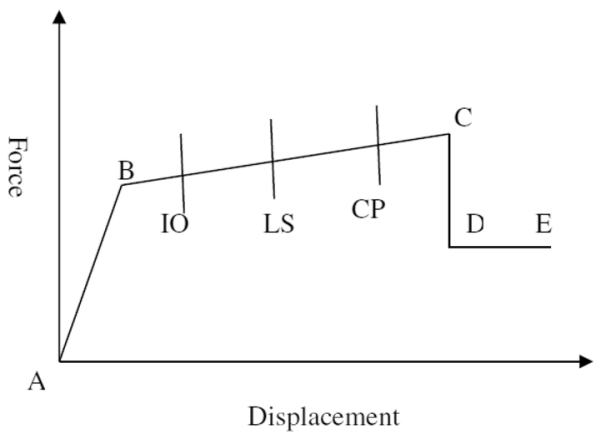

Fig. 2 Performance level for pushover analysis

\section{Computation of ' $R$ ' factor for the study water tanks}

Figures 4, 5, 6 and 7 show the pushover/capacity curves considering the $P-\Delta$ effects and their bilinear representations (dotted lines) for study elevated water tanks having a capacity of $140,480,1000$ and $2200 \mathrm{~m}^{3}$ supported on different soil conditions, respectively. To obtain useful information from the capacity curve, it is approximated by an idealized bilinear relationship using equal energy method. This method assumes that the area enclosed by the curve above the bilinear approximation is equal to the area enclosed by the curve below the bilinear approximation. The yielding of structures is evaluated according to the bilinear representations of the pushover curve. As mentioned earlier, two performance limits PL1 and PL2 are considered for the computation of ' $\mathrm{R}$ ' factor.

The parameters such as the maximum base shear $\left(V_{\mathrm{o}}\right)$, ultimate displacement $\left(\Delta_{\mathrm{u}}\right)$, yield base shear $\left(V_{\mathrm{d}}\right)$ and yield displacement $\left(\Delta_{\mathrm{y}}\right)$ required for the evaluation of response reduction factor are obtained from the pushover curves or from its bilinear approximation. The components of ' $R$ ' such as ductility ratio $(\mu)$, ductility factor $\left(R_{\mu}\right)$, and overstrength factor $\left(R_{\mathrm{S}}\right)$ for different water tanks are derived from these parameters corresponding to PL1 and are shown in Tables 10, 11, 12 and 13, respectively. An exact estimation of the impulsive and convective time period is necessary for the assessment of design base shear and realistic ' $R$ ' factor of a water tank.

The ' $R$ ' values corresponding to PL1 for the tanks resting on medium soil range from 3.17 to 8.92 for the four tanks considered, and are all higher than the IITK-GSDM guidelines/Draft IS 1893 (Part-2) specified value of $R(=2.5)$ for ductile/special moment resistance $\mathrm{RC}$ frame staging water tanks. The ' $R$ ' values corresponding to PL1 for 140, 480 and $2200 \mathrm{~m}^{3}$ water tanks supported on different soil types range from 4.49 to 11.93 , and are all higher than the IS 1893 (Part-2) 2014 specified value of $R(=4)$ for ductile/ special moment resistance RC frame staging water tanks. It is worth to mention that all the studied water tanks are constructed before the year 2014, and therefore, in this study it is assumed that it was designed using IITK-GSDMA guidelines/Draft IS 1893 (Part-2). This indicates that all the study water tanks were designed with higher safety margin than that of specified in Indian standards. It is worth to mention that the strength factor in a water tanks depends on various factors, such as the safety margins specified in the code, partial safety factors for loads and material strength. Furthermore, in same design code, strength factor becomes subjective to the individual designer's selection of crosssectional dimension depending on the demand, because the section and the percentage of reinforcement provided for a member are never exactly as per the demand requirements. For example, the same section will be provided for all the columns, although the design requirement usually varies for these. Additionally, the reinforcements provided are typically slightly more than the required due to the availability of discrete rebar sizes at site. This conservative decision imparted through a designer's choice adds to $R_{\mathrm{s}}$.

The pushover curves reflect that for all tanks, PL2 is reached after PL1 (i.e., at a larger displacement). According to pushover curves and their bilinearisation, maximum shear is almost the same as that of PL1. Since design shear do not change, reserve strength factor is also the same as in PL1. There is no change in yield displacement values for PL2 as compared to PL1. Ultimate displacement values for PL2 are larger as compared to PL1 values, and therefore, the ductility values are higher for PL2 as compared to PL1. Among

Table 6 Seismic performance levels (based on Table C1-3, FEMA 356)

\begin{tabular}{llll}
\hline & Immediate occupancy (IO) & Life safety (LS) & Collapse prevention (CP) \\
\hline Overall & Light & Moderate & Severe \\
Damage & Extensive cracking and hinge formation & Extensive damage to beams. Spalling of & Minor hairline cracking. \\
& in ductile elements. Limited cracking & cover and shear cracking $\left(<1 / 8^{\prime \prime}\right.$ width) & Limited yielding possible at a few \\
& and/or splice failure in some non-duc- & for ductile columns. Minor spalling in & locations. No crushing (strains \\
& tile columns. Severe damage in short & nonductile columns. Joint cracks $<1 / 8^{\prime \prime}$ & below 0.003). \\
& columns. & wide. & $1 \%$ transient; \\
Lateral drift limit & $1 \%$ transient; negligible & $1 \%$ transient; & $4 \%$ permanent \\
& permanent & $2 \%$ permanent &
\end{tabular}


Fig. 3 Finite element model of study tanks for pushover analysis

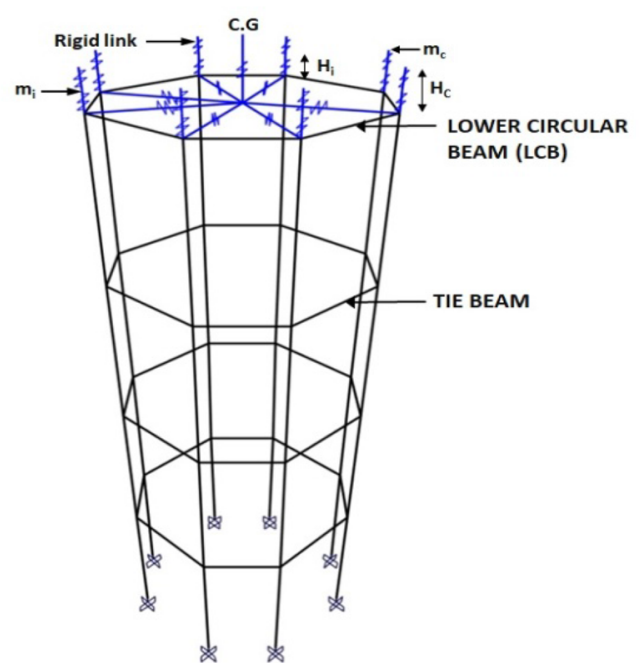

(b) $140 \mathrm{~m}^{3} \tan \mathrm{k}$

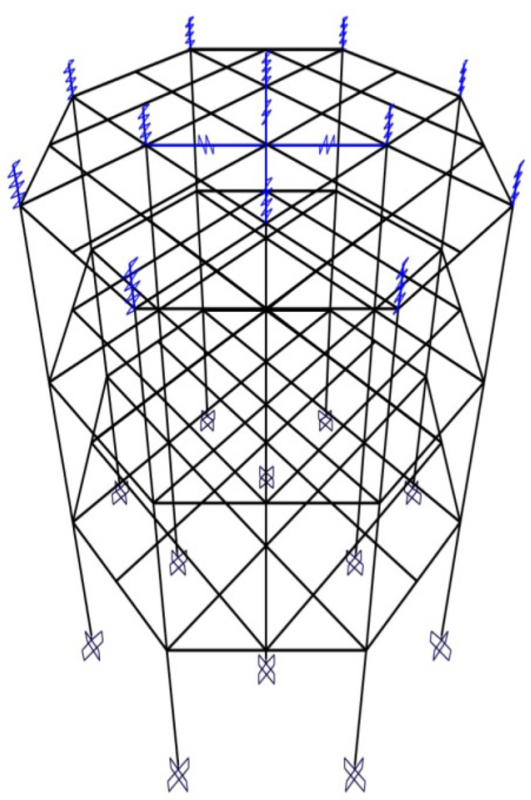

(b) $1000 \mathrm{~m}^{3} \operatorname{tank}$

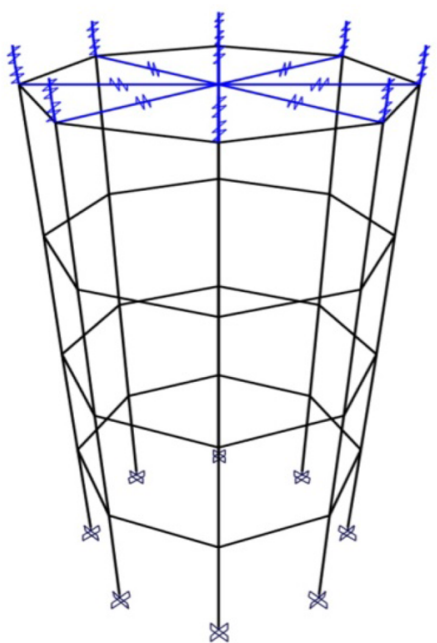

(b) $480 \mathrm{~m}^{3} \operatorname{tank}$

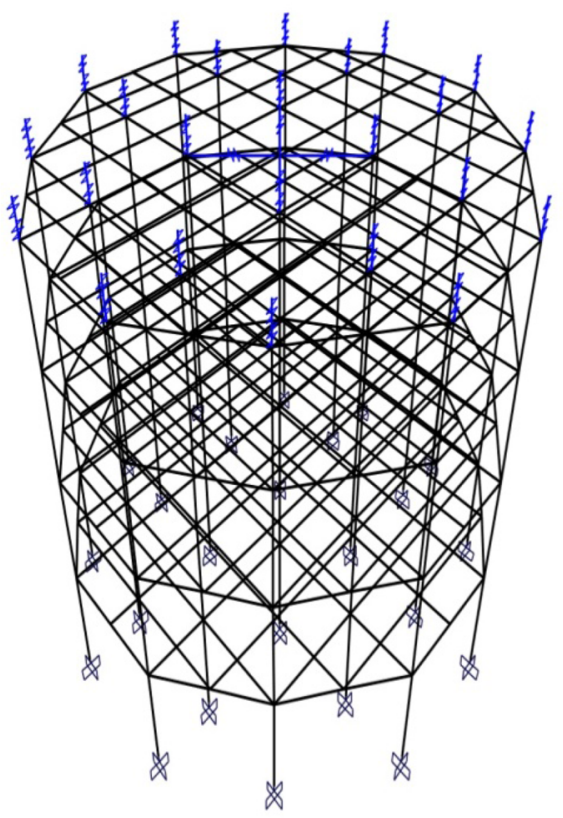

(b) $2200 \mathrm{~m}^{3} \operatorname{tank}$
Table 7 Plastic rotation limits for RC beams as per FEMA 356

\begin{tabular}{llllll}
\hline$\frac{p-p^{\prime}}{p_{\text {bal }}}$ & Trans reinf & $\frac{v}{b_{w} d \sqrt{ } f_{c}}$ & & \multicolumn{4}{c}{ Acceptance criteria } \\
\cline { 4 - 6 } & & & IO & LS & CP \\
\hline$\leq 0.0$ & $\mathrm{C}$ & $\leq 3$ & 0.010 & 0.02 & 0.025 \\
$\leq 0.0$ & $\mathrm{C}$ & $\leq 6$ & 0.005 & 0.01 & 0.02 \\
\hline
\end{tabular}

Table 8 Plastic rotation limits for RC columns as per FEMA 356

\begin{tabular}{llllll}
\hline$\frac{p-p^{\prime}}{p_{\text {bal }}}$ & Trans reinf & $\frac{v}{b_{w} d \sqrt{f_{c}}}$ & \multicolumn{4}{c}{ Acceptance criteria } \\
\cline { 4 - 6 } & & & IO & LS & CP \\
\hline$\leq 0.1$ & $\mathrm{C}$ & $\leq 3$ & 0.005 & 0.015 & 0.020 \\
$\leq 0.1$ & $\mathrm{C}$ & $\geq 6$ & 0.005 & 0.012 & 0.016 \\
$\geq 0.4$ & $\mathrm{C}$ & $\leq 3$ & 0.003 & 0.012 & 0.015 \\
$\geq 0.4$ & $\mathrm{C}$ & $\geq 6$ & 0.003 & 0.010 & 0.012 \\
\hline
\end{tabular}


Table 9 Deformation limits for different performance level

Performance level

\begin{tabular}{lllll}
\hline & $\begin{array}{l}\text { Immediate } \\
\text { occupancy }\end{array}$ & $\begin{array}{l}\text { Damage } \\
\text { control }\end{array}$ & Life safety & $\begin{array}{l}\text { Structural } \\
\text { stability }\end{array}$ \\
\hline $\begin{array}{c}\text { Maximum } \\
\text { drift ratio }\end{array}$ & 0.01 & $0.01-0.02$ & 0.02 & $0.33 V_{\mathrm{i}} / P_{\mathrm{i}}$ \\
\hline
\end{tabular}

the various components of ' $R$ ' presented in Tables 14, 15, 16 and 17, reserve strength factor $R_{\mathrm{s}}$ remains the same as in PL1, while ductility factor $R_{\mu}$ comes out to be higher, which finally results in higher ' $R$ ' factors overall. For PL2, ' $R$ ' ranges from 3.30 to 13.53 for all studied water tanks. Based on PL2, the IS 1893(Part-2): 2002 recommendation is on the conservative side. It should, however, be noted that this limit does not consider any member level behavior such as maximum plastic rotation at the ends. However, The actual value of ' $R$ ' of study water tanks needed to be even lower than what is evaluated in this study, because of many reasons, such as irregularity in dimensions leading to torsional effects, poor quality control and construction practice, not following ductile detailing requirements exactly as per the standards, and deterioration in concrete with time. If soil flexibility is not taken into account in estimating ' $R$ ' factor of elevated water tank properly, the accuracy in evaluating seismic base shear and assessing the structural safety for a structure subjected to earthquakes could not be reliable.

The effect of soil flexibility considerably increases the impulsive time period of the elevated water tank, indicating that modification in soil stiffness could have considerable effect on the fundamental period of vibration. It is observed that flexibility of supporting soil has considerable effect on base shear, ductility factor and response reduction factor of water tank. Considering soil flexibility, particularly when the tank supported on relatively soft soil is crucial. The increase in the flexibility of the soil reduces the overstrength factor as well as ductility factor of study water tanks. The consideration of soil flexibility in analysis reduces the values of ' $R$ ' factor of study water tanks as compared to fixed base condition. The overstrength factor as well as ductility factor reduce with increase in the size of the study water tank. Consideration of flexibility of soft and medium soil in analysis reduces the values of ' $R$ ' factor as much as 25 and $40 \%$ for the considered tanks, respectively, as compared to fixed base condition. The effect of the soil flexibility is the least in case of hard soil.

The response reduction factors of 140, 480 and $2200 \mathrm{~m}^{3}$ water tanks are also evaluated for the higher seismically intensive zone-IV to check its suitability for that zone. Tables 14, 15, and 16 show the response reduction factor and its components for 140,480 and $2200 \mathrm{~m}^{3}$ water
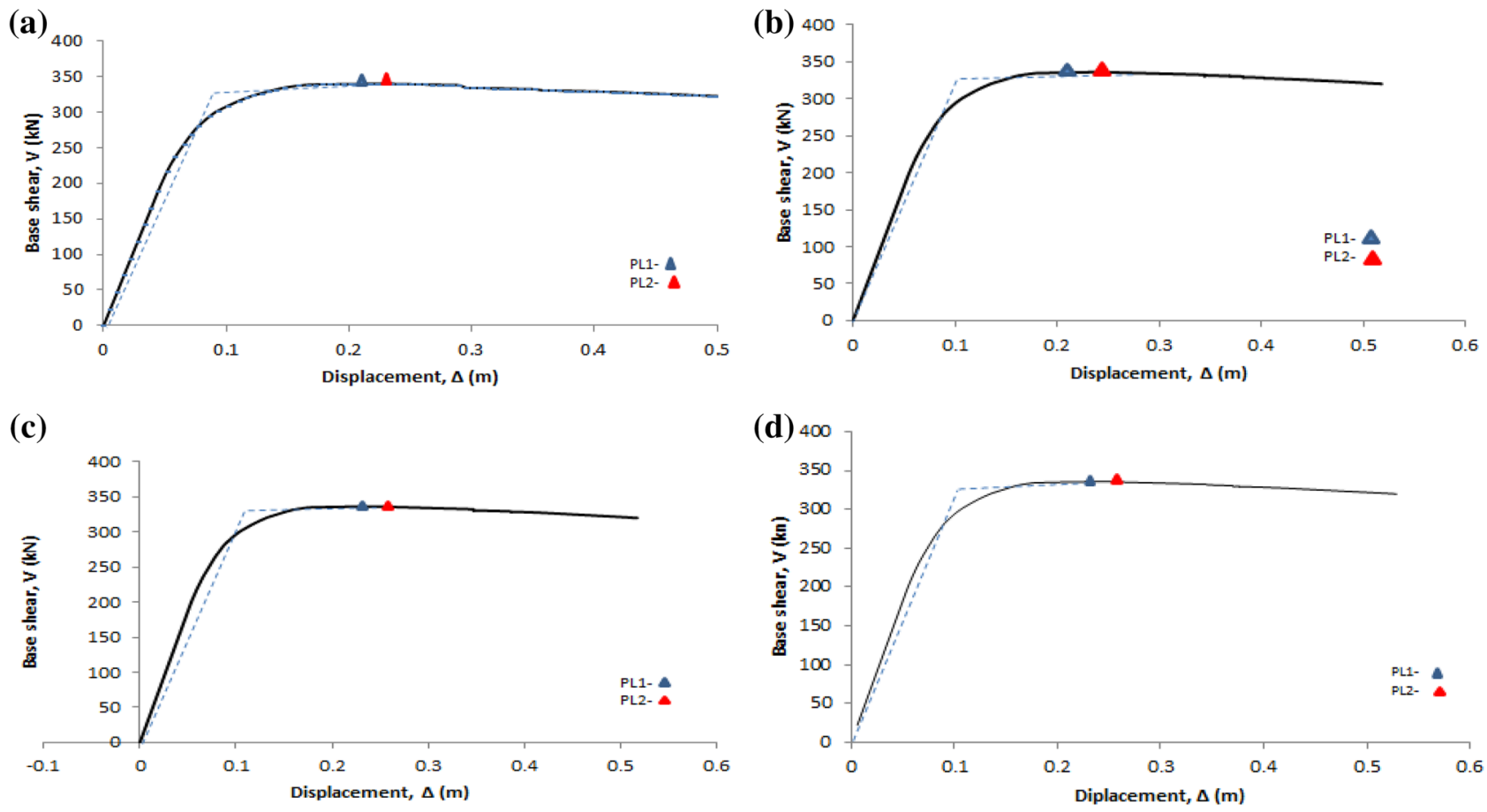

Fig. 4 a Pushover curve for $140 \mathrm{~m}^{3}$ tank with fixed base. b Pushover curve for $140 \mathrm{~m}^{3}$ tank on hard soil. c Pushover curve for $140 \mathrm{~m}^{3}$ tank on medium soil. d Pushover curve for $140 \mathrm{~m}^{3}$ tank on soft soil 

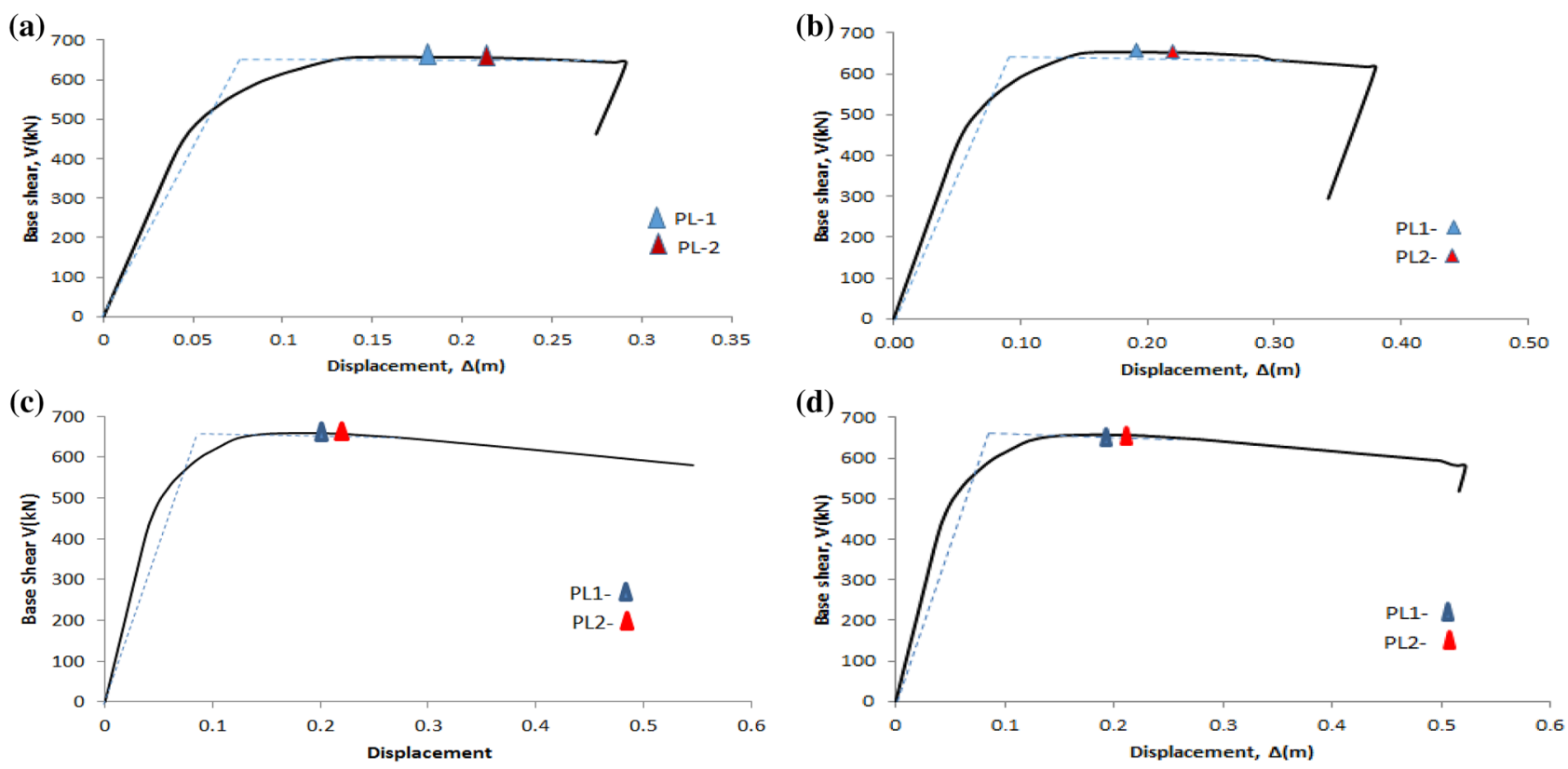

Fig. 5 a Pushover curve for $480 \mathrm{~m}^{3}$ tank with fixed base. b Pushover curve for $480 \mathrm{~m}^{3}$ tank on hard soil. c Pushover curve for $480 \mathrm{~m}^{3}$ tank on medium soil. d Pushover curve for $480 \mathrm{~m}^{3}$ tank on soft soil
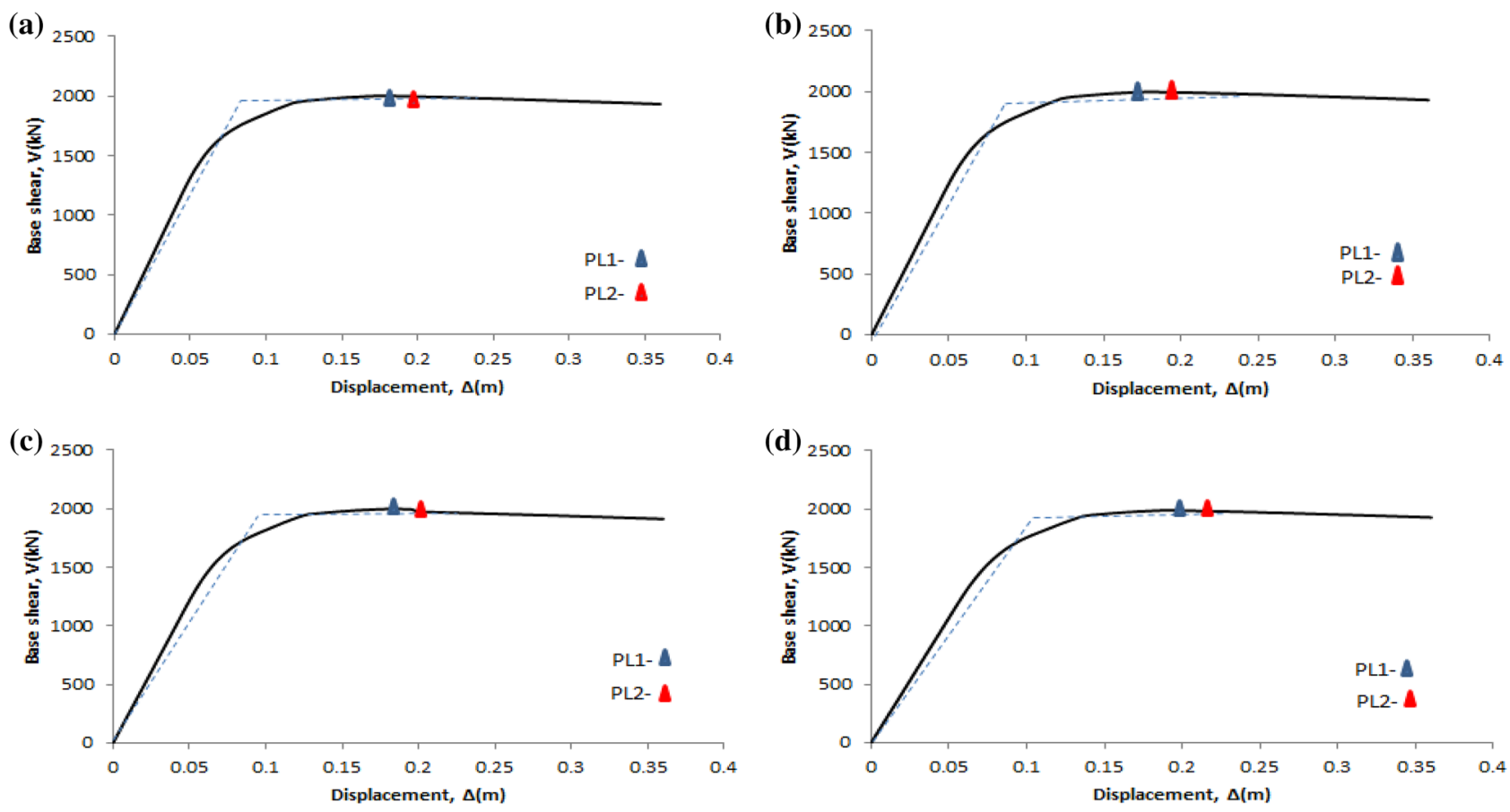

Fig. 6 a Pushover curve for $1000 \mathrm{~m}^{3}$ tank with fixed based. b Pushover curve for $1000 \mathrm{~m}^{3}$ tank on hard soil. c Pushover curve for $1000 \mathrm{~m}^{3}$ tank on medium soil. d Pushover curve for $1000 \mathrm{~m}^{3}$ tank on soft soil

tanks, respectively, for seismic zone-III and -IV. Table 17 shows the response reduction factor and its components for $1000 \mathrm{~m}^{3}$ water tanks for seismic zone-V for PL2. The ' $R$ ' factors of these three tanks for different supporting soil conditions range from 3 to 8.7 and 3.57 to 9.09 for PL1 and PL2, respectively, for seismic zone-IV. All the evaluated values of ' $R$ ' factor are higher than the IIITK-GSDMA and Draft IS 1893 (Part-II) guidelines suggested value of $R(=2.5)$ for ductile/special moment resistance RC frame staging water tanks, indicating that these three water tanks 

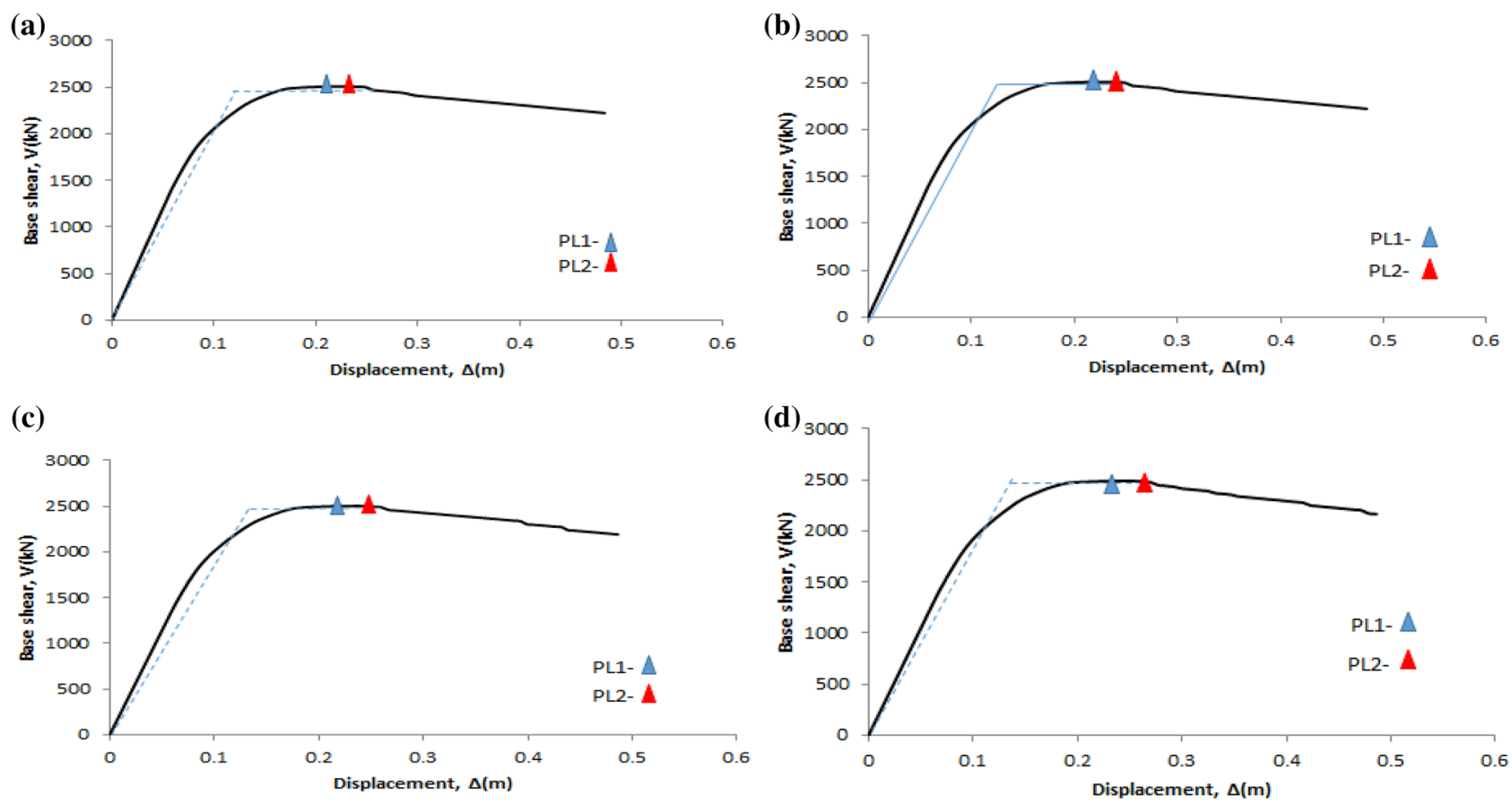

Fig. 7 a Pushover curve for $2200 \mathrm{~m}^{3}$ tank with fixed base. b Pushover curve for $2200 \mathrm{~m}^{3}$ tank on hard soil. c Pushover curve for $2200 \mathrm{~m}^{3}$ on medium soil. d Pushover curve for $2200 \mathrm{~m}^{3}$ tank on soft soil

Table 10 Component-wise evaluation of ' $\mathrm{R}$ ' based on PL1 for $140 \mathrm{~m}^{3}$ tank (Zone-III)

\begin{tabular}{lllllllllll}
\hline Type of soil & $\begin{array}{l}T_{\mathrm{i}(\mathrm{sec})} \\
\text { (impul- } \\
\text { sive) }\end{array}$ & $\begin{array}{l}V_{0} \\
(\mathrm{kN})\end{array}$ & $\begin{array}{l}V_{\mathrm{d}} \\
(\mathrm{kN})\end{array}$ & $R_{\mathrm{s}}=V_{0} / V_{\mathrm{d}}$ & $\begin{array}{l}\Delta_{\mathrm{m}} \\
(\mathrm{mm})\end{array}$ & $\begin{array}{c}\Delta_{\mathrm{y}} \\
(\mathrm{mm})\end{array}$ & $\mu=\Delta_{\mathrm{m}} / \Delta_{\mathrm{y}}$ & $R_{\mu}$ & $R_{\mathrm{R}}$ & $R$ \\
\hline Fixed & 1.22 & 340 & 70 & 4.85 & 211 & 92 & 2.29 & 2.67 & 1 & 12.94 \\
Hard & 1.31 & 336 & 66 & 5.09 & 211 & 103 & 2.05 & 2.34 & 1 & 11.93 \\
Medium & 1.36 & 336 & 84 & 4.01 & 209 & 107 & 1.97 & 2.23 & 1 & 8.92 \\
Soft & 1.64 & 335 & 85 & 3.94 & 211 & 110 & 1.91 & 2.29 & 1 & 9.02 \\
\hline
\end{tabular}

\begin{tabular}{lllllllllll}
\hline Type of soil & $\begin{array}{l}T_{\mathrm{i}(\mathrm{sec})} \\
\text { (impul- } \\
\text { sive) }\end{array}$ & $\begin{array}{l}V_{0} \\
(\mathrm{kN})\end{array}$ & $\begin{array}{l}V_{\mathrm{d}} \\
(\mathrm{kN})\end{array}$ & $R_{\mathrm{s}}=\underline{V}_{0} / V_{\mathrm{d}}$ & $\begin{array}{l}\Delta_{\mathrm{m}} \\
(\mathrm{mm})\end{array}$ & $\begin{array}{l}\Delta_{\mathrm{y}} \\
(\mathrm{mm})\end{array}$ & $\mu=\Delta_{\mathrm{m}} / \Delta_{\mathrm{y}}$ & $R \mu$ & $R_{\mathrm{R}}$ & $R$ \\
\hline Fixed & 1.22 & 663 & 175 & 3.78 & 189 & 83 & 2.27 & 2.61 & 1 & 9.86 \\
Hard & 1.24 & 659 & 173 & 3.80 & 190 & 86 & 2.20 & 2.53 & 1 & 9.61 \\
Medium & 1.25 & 657 & 230 & 2.85 & 186 & 92 & 2.02 & 2.34 & 1 & 6.66 \\
Soft & 1.28 & 653 & 273 & 2.39 & 186 & 94 & 1.97 & 2.35 & 1 & 5.61 \\
\hline
\end{tabular}

Table 11 Component-wise evaluation of ' $R$ ' based on PL1 for $480 \mathrm{~m}^{3} \operatorname{tank}$ (Zone-III) of water tank. In case of $2200 \mathrm{~m}^{3}$ water tank, consideration of flexibility of medium and soft soil in analysis reduces ductility factor as much as 11 and $14 \%$ as compared to fixed base condition. For all the studied water tanks, consideration of soil flexibility in computation of ' $R$ ' factor reduces the ductility factor as much as $14 \%$ as compared to the ideal fixed base condition. 
Table 12 Component-wise evaluation of ' $R$ ' based on PL1 for $1000 \mathrm{~m}^{3}$ tank (Zone-V)
Table 13 Component-wise evaluation of ' $R$ ' based on PL1 for $2200 \mathrm{~m}^{3}$ tank (Zone-III)
Table 14 Component of ' $R$ ' for $140 \mathrm{~m}^{3}$ based on PL1 and PL2 for seismic zone-III and IV

\begin{tabular}{llllllllllll}
\hline Type of soil & $\begin{array}{l}T_{\mathrm{i}(\mathrm{sec})} \\
(\mathrm{impul}- \\
\text { sive) }\end{array}$ & $\begin{array}{l}V_{0} \\
(\mathrm{kN})\end{array}$ & $\begin{array}{l}V_{\mathrm{d}} \\
(\mathrm{kN})\end{array}$ & $R_{\mathrm{s}}=V_{0} / V_{\mathrm{d}}$ & $\begin{array}{c}\Delta_{\mathrm{m}} \\
(\mathrm{mm})\end{array}$ & $\begin{array}{c}\Delta_{\mathrm{y}} \\
(\mathrm{mm})\end{array}$ & $\mu=\Delta_{\mathrm{m}} / \Delta_{\mathrm{y}}$ & $R_{\mu}$ & $R_{\mathrm{R}}$ & $R$ \\
\hline Fixed & 1.21 & 2000 & 987 & 2.02 & 176 & 83 & 2.12 & 2.42 & 1 & 4.88 \\
Hard & 1.25 & 1996 & 954 & 2.09 & 179 & 87 & 2.05 & 2.35 & 1 & 4.91 \\
Medium & 1.29 & 1996 & 1232 & 1.62 & 180 & 90 & 2.00 & 2.29 & 1 & 3.70 \\
Soft & 1.35 & 1988 & 1446 & 1.37 & 194 & 102 & 1.90 & 2.27 & 1 & 3.10 \\
\hline
\end{tabular}

\begin{tabular}{lllllllllll}
\hline Type of soil & $\begin{array}{l}T_{\mathrm{i}(\mathrm{sec})} \\
\text { (impul- } \\
\text { sive) }\end{array}$ & $\begin{array}{l}V_{0} \\
(\mathrm{kN})\end{array}$ & $\begin{array}{l}V_{\mathrm{d}} \\
(\mathrm{kN})\end{array}$ & $R_{\mathrm{s}}=V_{0} / V_{\mathrm{d}}$ & $\begin{array}{l}\Delta_{\mathrm{m}} \\
(\mathrm{mm})\end{array}$ & $\begin{array}{l}\Delta_{\mathrm{y}} \\
(\mathrm{mm})\end{array}$ & $\mu=\Delta_{\mathrm{m}} / \Delta_{\mathrm{y}}$ & $R_{\mu}$ & $R_{\mathrm{R}}$ & $R$ \\
\hline Fixed & 1.55 & 2505 & 659 & 2.79 & 218 & 110 & 1.81 & 2.05 & 1 & 7.79 \\
Hard & 1.57 & 2505 & 650 & 3.85 & 224 & 120 & 1.70 & 1.91 & 1 & 7.35 \\
Medium & 1.61 & 2500 & 835 & 2.99 & 235 & 124 & 1.70 & 1.82 & 1 & 5.44 \\
Soft & 1.70 & 2485 & 966 & 2.57 & 258 & 148 & 1.50 & 1.75 & 1 & 4.49 \\
\hline
\end{tabular}

\begin{tabular}{|c|c|c|c|c|c|c|c|c|c|c|c|c|}
\hline \multicolumn{7}{|c|}{$140 \mathrm{~m}^{3}$ capacity (zone-III) } & \multicolumn{6}{|c|}{$140 \mathrm{~m}^{3}$ capacity (zone-IV) } \\
\hline \multirow[t]{2}{*}{ Type of soil } & \multirow[t]{2}{*}{$R_{\mathrm{s}}$} & \multirow[t]{2}{*}{$R_{\mathrm{R}}$} & \multicolumn{2}{|l|}{ PL1 } & \multicolumn{2}{|l|}{ PL2 } & \multirow[t]{2}{*}{$R_{\mathrm{s}}$} & \multirow[t]{2}{*}{$R_{\mathrm{r}}$} & \multicolumn{2}{|l|}{ PL1 } & \multicolumn{2}{|l|}{ PL2 } \\
\hline & & & $R_{\mu}$ & $R$ & $R_{\mu}$ & $R$ & & & $R_{\mu}$ & $R$ & $R_{\mu}$ & $R$ \\
\hline Fixed & 4.85 & 1 & 2.67 & 12.94 & 2.79 & 13.53 & 3.26 & 1 & 2.67 & 8.70 & 2.79 & 9.09 \\
\hline Hard & 5.1 & 1 & 2.34 & 11.93 & 2.58 & 13.15 & 3.42 & 1 & 2.34 & 8.0 & 2.58 & 8.82 \\
\hline Medium & 4.01 & 1 & 2.23 & 8.92 & 2.55 & 10.19 & 2.68 & 1 & 2.23 & 5.97 & 2.55 & 6.83 \\
\hline Soft & 3.94 & 1 & 2.29 & 9.02 & 2.53 & 9.96 & 2.63 & 1 & 2.29 & 6.02 & 2.53 & 6.65 \\
\hline
\end{tabular}

Table 15 Component of ' $R$ ' for $480 \mathrm{~m}^{3}$ based on PL1 and PL2 for seismic zone-III and IV

\begin{tabular}{|c|c|c|c|c|c|c|c|c|c|c|c|c|}
\hline \multicolumn{7}{|c|}{$480 \mathrm{~m}^{3}$ capacity (zone-III) } & \multicolumn{6}{|c|}{$480 \mathrm{~m}^{3}$ capacity (zone-IV) } \\
\hline \multirow[t]{2}{*}{ Type of soil } & \multirow[t]{2}{*}{$R_{\mathrm{s}}$} & \multirow[t]{2}{*}{$i_{R}$} & \multicolumn{2}{|l|}{ PL1 } & \multicolumn{2}{|l|}{ PL2 } & \multirow[t]{2}{*}{$R_{\mathrm{S}}$} & \multirow[t]{2}{*}{$R_{\mathrm{R}}$} & \multicolumn{2}{|l|}{ PL1 } & \multicolumn{2}{|l|}{ PL2 } \\
\hline & & & $R_{\mu}$ & $R$ & $R_{\mu}$ & $R$ & & & $R_{\mu}$ & $R$ & $R_{\mu}$ & $R$ \\
\hline Fixed & 3.78 & 1 & 2.61 & 9.86 & 2.96 & 11.18 & 2.52 & 1 & 2.61 & 6.57 & 2.96 & 7.45 \\
\hline Hard & 3.8 & 1 & 2.53 & 9.61 & 2.76 & 10.48 & 2.53 & 1 & 2.53 & 6.41 & 2.76 & 6.98 \\
\hline Medium & 2.85 & 1 & 2.34 & 6.66 & 2.50 & 7.12 & 1.90 & 1 & 2.34 & 4.46 & 2.50 & 4.75 \\
\hline Soft & 2.39 & 1 & 2.35 & 5.61 & 2.46 & 5.87 & 1.59 & 1 & 2.35 & 3.75 & 2.46 & 3.91 \\
\hline
\end{tabular}

\section{Conclusions}

In this study, the ' $R$ ' factors of four existing RC-elevated water tanks designed using IS 456, Draft IS $1893 *$ Part-II) and detailed as per IS 13920 are evaluated considering soil flexibility. The focus has been given in methodical assessment of the $R$ factor, consideration of soil flexibility; realistic performance-based limit states at both structure and member levels. The schematic procedure for evaluating the realistic values of response reduction factor of RC staging elevated water tank incorporating the effect of soil flexibility, is also presented. The use of realistic values of response reduction factor may prove useful for safe and economic seismic design of elevated water tank. The significant observations of the present study are summarized as follows:

- The $R$ values corresponding to PL1 for the tanks resting on medium soil range from 3.17 to 8.92 for the four tanks considered, and all are higher compared to the IITK-GSDM guidelines/Draft IS 1893 (Part-II) suggested value of $R(=2.5)$ for ductile/special moment resistance $\mathrm{RC}$ frame staging water tanks. This indicates that all the 
Table 16 Component of ' $R$ ' for $2200 \mathrm{~m}^{3}$ based on PL1 and PL2 for seismic zone-III and IV

\begin{tabular}{|c|c|c|c|c|c|c|c|c|c|c|c|c|}
\hline \multicolumn{7}{|c|}{$2200 \mathrm{~m}^{3}$ capacity (zone-III) } & \multicolumn{6}{|c|}{$2200 \mathrm{~m}^{3}$ capacity (zone- IV) } \\
\hline \multirow[t]{2}{*}{ Type of soil } & \multirow[t]{2}{*}{$R_{\mathrm{s}}$} & \multirow[t]{2}{*}{$R_{\mathrm{R}}$} & \multicolumn{2}{|l|}{ PL1 } & \multicolumn{2}{|l|}{ PL2 } & \multirow[t]{2}{*}{$\mathrm{R}_{\mathrm{s}}$} & \multirow[t]{2}{*}{$\mathrm{R}_{\mathrm{R}}$} & \multicolumn{2}{|l|}{ PL1 } & \multicolumn{2}{|l|}{ PL2 } \\
\hline & & & $R_{\mu}$ & $R$ & $R_{\mu}$ & $R$ & & & $R_{\mu}$ & $R$ & $R_{\mu}$ & $R$ \\
\hline Fixed & 3.79 & 1 & 2.05 & 7.79 & 2.27 & 8.60 & 2.54 & 1 & 2.05 & 5.20 & 2.27 & 5.76 \\
\hline Hard & 3.85 & 1 & 1.91 & 7.35 & 2.11 & 8.12 & 2.57 & 1 & 1.91 & 4.92 & 2.11 & 5.42 \\
\hline Medium & 2.99 & 1 & 1.82 & 5.44 & 2.04 & 6.11 & 1.99 & 1 & 1.82 & 3.64 & 2.04 & 4.05 \\
\hline Soft & 2.57 & 1 & 1.75 & 4.49 & 2.09 & 5.37 & 1.71 & 1 & 1.75 & 3.00 & 2.09 & 3.57 \\
\hline
\end{tabular}

Table 17 Component of ' $R$ ' for $1000 \mathrm{~m}^{3}$ based on PL1 and PL2 for seismic zone-V

\begin{tabular}{|c|c|c|c|c|c|c|}
\hline \multicolumn{7}{|c|}{$1000 \mathrm{~m}^{3}$ capacity (zone-V) } \\
\hline \multirow[t]{2}{*}{ Type of soil } & \multirow[t]{2}{*}{$R_{\mathrm{s}}$} & \multirow[t]{2}{*}{$R_{\mathrm{R}}$} & \multicolumn{2}{|l|}{ PL1 } & \multicolumn{2}{|l|}{ PL2 } \\
\hline & & & $R_{\mu}$ & $R$ & $R_{\mu}$ & $R$ \\
\hline Fixed & 2.02 & 1 & 2.42 & 4.88 & 2.62 & 5.30 \\
\hline Hard & 2.09 & 1 & 2.35 & 4.91 & 2.50 & 5.230 \\
\hline Medium & 1.62 & 1 & 2.29 & 3.70 & 2.50 & 4.07 \\
\hline Soft & 1.37 & 1 & 2.27 & 3.1 & 2.40 & 3.30 \\
\hline
\end{tabular}
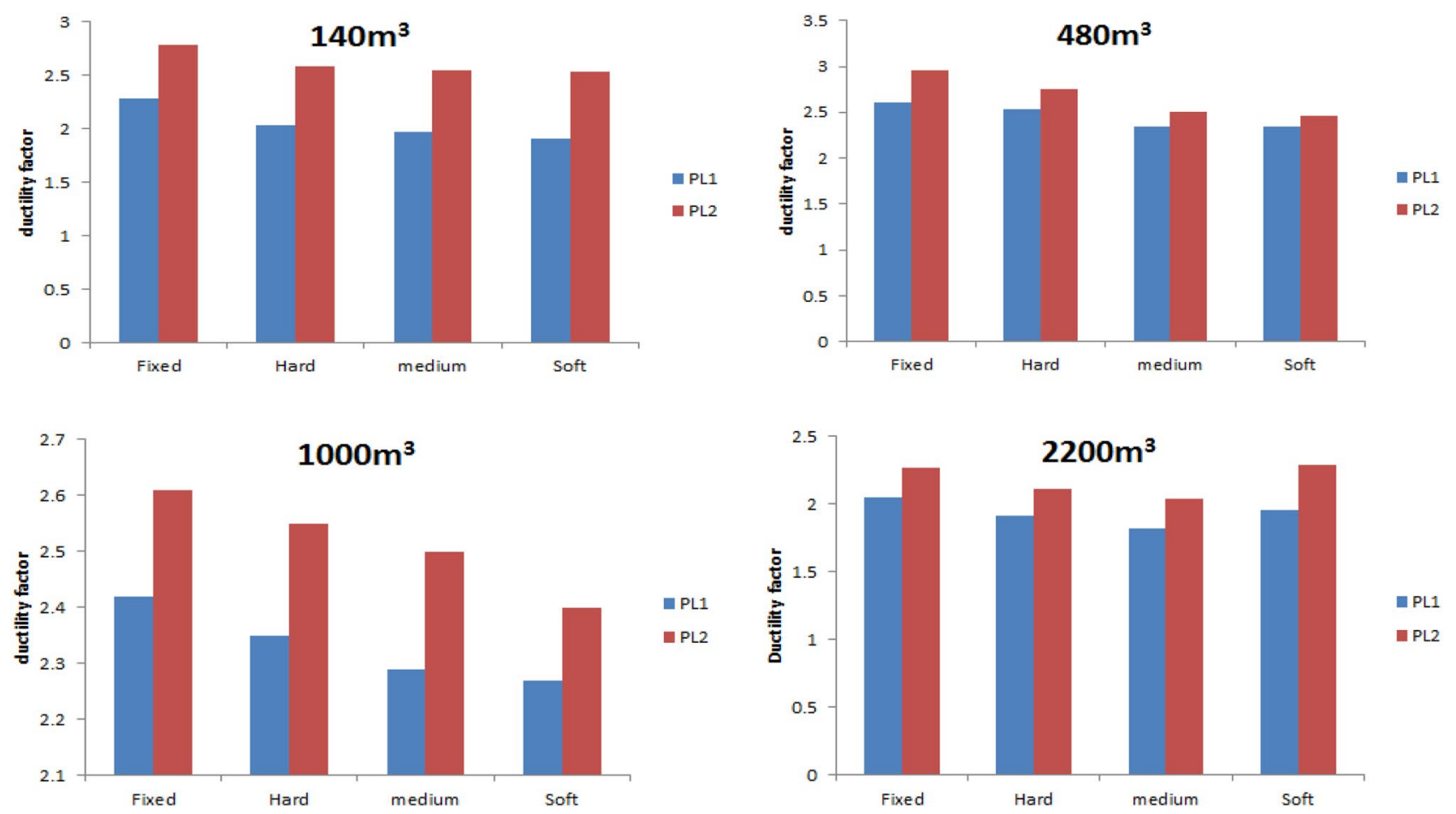

Fig. 8 Ductility factor of study water tank for different soil conditions

studied water tanks were designed with higher safety margin.

- Based on PL2, $R$ factor ranges from 3.30 to 13.53 , indicating the IITK-GSDM guidelines recommendation is on the conservative side.
- As the soil spring stiffness decrease from hard to soft soil, the impulsive time period of elevated water tank model increases and response reduction factor decreases. This means that the impulsive time period and response reduction factor is also a function of soil flexibility. 
- The overstrength factor as well as ductility factor reduce with the increase of the size of the studied water tanks.

- The flexibility of supporting soil has considerable effect on displacement ductility and response reduction factor of water tanks. Consideration of flexibility of medium and soft soil in analysis reduces the values of ' $R$ ' factor as much as 25 and $40 \%$ for the considered tanks, respectively, as compared to fixed base condition. The effect of the soil flexibility is the least in case of hard soil. The analysis of water tank with fixed base assumption may lead to underestimation or overestimation of seismic base shear of elevated tanks with any staging configurations.

- Consideration of flexibility of medium and soft soil during analysis increases yield and ultimate displacement response demands compared to that of fixed base model Consideration of flexibility of medium and soft soil during analysis reduces the displacement ductility ratio $(\mu)$ of water tank models as much as $12 \%$ and $16 \%$ for the considered tanks, respectively, as compared to fixed base condition.

- The actual value of ' $R$ ' of study water tanks needed to be even smaller than what is evaluated in this study, because of various reasons, such as poor quality control and workmanship during the construction, irregularity in dimensions leading to torsional effects, and not following the ductile detailing requirements exactly as per the standards which would lead to deterioration in concrete with time.

Acknowledgements The authors acknowledge the financial support from a project sanctioned by Gujarat Council on Science and Technology, Government of Gujarat, Gujarat, India (Order No. GUJCOST/ MRP/15-16/1905) for successful completion of this work.

Open Access This article is distributed under the terms of the Creative Commons Attribution 4.0 International License (http://creativeco mmons.org/licenses/by/4.0/), which permits unrestricted use, distribution, and reproduction in any medium, provided you give appropriate credit to the original author(s) and the source, provide a link to the Creative Commons license, and indicate if changes were made.

\section{References}

ACI 350.3 (2001) Seismic design of liquid containing concrete structures. American Concrete Institute Standard, Farmington Hills

ATC 19 (1995) Structural response modification factors. Applied Technology Council, Redwood City, USA

ATC-40 (1996) Seismic evaluation and retrofit of concrete building, vol 1. Seismic Safety Commission, Redwood City, USA

AWWA D-110 (1995) Wire- and strand-wound circular, prestressed concrete water tanks. American Water Works Association, Colorado, USA
BIS IS 13920 (1993) Ductile detailing of reinforced concrete structure subjected to seismic forces-code of practise. Bureau of Indian Standards, New Delhi, India

BIS IS 1893 (2014) Criteria for earthquake resistant design of structures, Part 2. Bureau of Indian Standards, New Delhi, India

BIS IS 456 (2000) Plain and reinforced concrete-code of practice. Bureau of Indian Standards, New Delhi, India

Draft IS 1893 (2006) Criteria for earthquake resistant design of strucutres, Part 2. Liquid retaining tanks. Bureau of Indian Standards, New Delhi, India (Doc No. CED 39 (7231))

Dutta SC, Jain SK, Murty CVR (2000) Assessing the seismic torsional vulnerability of elevated tanks with RC frame-type staging. Soil Dyn Earthq Eng 19:183-197

Dutta S, Mandal A, Dutta SC (2004) Soil-structure interaction in dynamic behavior of elevated tanks with alternate frame staging configurations. J Sound Vib 277:825-853

FEMA 356 (2000) Prestandard and commentary for the seismic rehabilitation of buildings. Federal Emergency Management Agency, Washington D.C., USA

FEMA 368 (2000) NEHRP recommended provisions for seismic regulations for new buildings and other structures - part 1: provisions. Building Seismic Safety Council, Washington D.C., USA

Ghateh R, Kianoush MR, Pogorzelski W (2015) Seismic response factor of RC pedestal in elevated water tanks. Eng Struct 87:32-46

Ghazetas G (1983) Analysis of machine foundation vibrations: state of art. Soil Dyn Earthq Eng 2(1):2-42

Halabian AM, Erfani M (2013) The effect of foundation flexibility and structural strength on response reduction factor of $\mathrm{RC}$ frame structures. Struct Des Tall Spec Build 22:1-28

IBC (2000) International Building Code 2000. International Code Council, Falls Church

IITK-GSDM guidelines for Seismic design of liquid storage tanks (2007), NICEE, Indian Institute of Technology, Kanpur, India

IS 1893 (2002) Indian standard criteria for earthquake resistant design of structures, Part-1, Bureau of Indian Standards, New Delhi, India

Krawinkler H, Nassar A (1992) Nonlinear seismic analysis of reinforced concrete buildings. Seismic design based on ductility and cumulative damage demands and capacities. CRC Press, New York, pp 27-47

Livaoglu R, Dogangun A (2007) Effect of foundation embedment on seismic behavior of elevated tanks considering fluid-structure-soil interaction". Soil Dyn Earthq Eng 27:855-863

Miranda E, Bertero V (1994) Evaluation of strength reduction factors for earthquake resistantdesign. Earthq Spectra 10:357-379

Mondal A, Ghosh S, Reddy GR (2013) Performance based evaluation of the response reduction factor for ductile RC frames. Eng Struct 56:1808-1819

Mostafa M, Sassan E, Mohsen G (2012) Evaluation of response modification factor $(\mathrm{R})$ of elevated concrete tanks. Eng Struct 39:199-209

Newmark N, Hall W (1982) Earthquake spectra and design. Engineering monograph. Earthquake Engineering Research Institute, Berkeley

Patel T, Amin JA, Patel B (2014) Evaluation of response reduction factor of RC framed staging elevated water tank using static pushover analysis. Int J Civil Struct Eng 4(3):215-226

Rai DC (2003) Performance of elevated tanks in Mw 7.7 Bhuj earthquake of January 26th, 2001. Proc Indian Acad Sci Earth Planet Sci 112:421-429

Riddell R, Newmark N (1979) Statistical analysis of the response of nonlinear systems subjected to earthquakes, vol 468. Structural research series. Dept. of Civil Engineering, University of Illinois, Urbana 
Structural Analysis software (2000) Advance, static and dynamic finite element analysis of structures, SAP 2000. Computer and Structures, Inc, Berkeley

Tamboli K, Amin JA (2015) Evaluation of response reduction factor of RC braced frame. J Mater Eng Struct 2:120-129
Publisher's Note Springer Nature remains neutral with regard to jurisdictional claims in published maps and institutional affiliations. 